\title{
Targeting hedgehog signalling by arsenic trioxide reduces cell growth and induces apoptosis in rhabdomyosarcoma
}

\author{
KAREN A. BOEHME ${ }^{1}$, JULIAN J. ZABORSKI ${ }^{1}$, ROSA RIESTER $^{1}$, SABRINA K. SCHWEISS $^{1,2}$, ULRIKE HOPP $^{1}$, \\ FRANK TRAUB $^{3}$, TORSTEN KLUBA ${ }^{3,4}$, RUPERT HANDGRETINGER ${ }^{5}$ and SABINE B. SCHLEICHER ${ }^{5}$ \\ ${ }^{1}$ Laboratory of Cell Biology, Department of Orthopaedic Surgery, Eberhard Karls University Tuebingen, Tuebingen; \\ ${ }^{2}$ Faculty of Applied Natural Sciences, Esslingen University, Esslingen; ${ }^{3}$ Department of Orthopaedic Surgery, \\ Eberhard Karls University, Tuebingen; ${ }^{4}$ Department for Orthopaedic Surgery, Hospital Dresden-Friedrichstadt, Dresden; \\ ${ }^{5}$ Department of Haematology and Oncology, Children's Hospital, Eberhard Karls University Tuebingen, Tuebingen, Germany
}

Received August 6, 2015; Accepted November 12, 2015

DOI: $10.3892 /$ ijo.2015.3293

\begin{abstract}
Rhabdomyosarcomas (RMS) are soft tissue tumours treated with a combination of surgery and chemotherapy. However, mortality rates remain high in case of recurrences and metastatic disease due to drug resistance and failure to undergo apoptosis. Therefore, innovative approaches targeting specific signalling pathways are urgently needed. We analysed the impact of different hedgehog $(\mathrm{Hh})$ pathway inhibitors on growth and survival of six RMS cell lines using MTS assay, colony formation assay, 3D spheroid cultures, flow cytometry and western blotting. Especially the glioma-associated oncogene family (GLI) inhibitor arsenic trioxide (ATO) effectively reduced viability as well as clonal growth and induced cell death in RMS cell lines of embryonal, alveolar and sclerosing, spindle cell subtype, whereas normal skeletal muscle cells were hardly compromised by ATO. Combination of ATO with itraconazole potentiated the reduction of colony formation and spheroid size. These results show that ATO is a promising substance for treatment of relapsed and refractory RMS by
\end{abstract}

Correspondence to: Dr Karen A. Boehme, Laboratory of Cell Biology, Department of Orthopaedic Surgery, Eberhard Karls University Tuebingen, Waldhoernlestrasse 22, D-72072 Tuebingen, Germany

E-mail: karen.boehme@med.uni-tuebingen.de

Abbreviations: APL, acute promyelocytic leukemia; ATO, arsenic trioxide; BAD, BCL2-associated agonist of cell death; BAX, BCL2-associated X-protein; BCL, B-cell CLL/lymphoma 2; CDK2, cyclin-dependent kinase 2; CDKN1C, cyclin-dependent kinase inhibitor 1C; FOXO1, forkhead box O1; GLI, glioma-associated oncogene family; Hh, hedgehog; PARP, poly(ADP-ribose) polymerase; PTCH, patched; PAX, paired box; RMS, rhabdomyosarcoma; SKMC, skeletal muscle cells; SMO, smoothened; TRAIL, TNF-related apoptosis inducing ligand

Key words: rhabdomyosarcoma, hedgehog signalling, arsenic trioxide, GANT61, itraconazole, cyclopamine, LDE225 directly targeting GLI transcription factors. The combination with itraconazole or other chemotherapeutic drugs has the opportunity to enforce the treatment efficiency of resistant and recurrent RMS.

\section{Introduction}

Rhabdomyosarcomas (RMS) are the most common paediatric soft tissue tumours, accounting for $\sim 5 \%$ of all cancers at that age. Several histologic RMS variants can be differentiated with two thirds of RMS belonging to the embryonal subtype (ERMS) usually diagnosed in younger children below the age of 6 years. The more aggressive alveolar subtype (ARMS), which is more common in adolescents and young adults, makes up $\sim 20 \%$ of new cases. ARMS are characterised by the reciprocal translocations $\mathrm{t}(2 ; 13)(\mathrm{p} 35 ; \mathrm{q} 14)$ or $\mathrm{t}(1 ; 13)(\mathrm{p} 36 ; \mathrm{q} 14)$ leading to the expression of fusion proteins consisting of the DNA-binding domains of PAX3 or PAX7 and the transactivation domain of FOXO1 $(1,2)$. ERMS often exhibit loss of heterozygosity (LOH) at the chromosomal band $11 \mathrm{p} 15.5$ affecting the expression of the tumour suppressor genes $H 19$ and $C D K N 1 C$ (2). There are additional subtypes as the high grade pleomorphic RMS with a very unfavourable prognosis (3) and the sclerosing, spindle cell variant. In children this subtype often has a favourable outcome, whereas in adults it is highly aggressive $(4,5)$.

The standard therapy of RMS is surgery combined with a first line chemotherapy composed of vincristine, actinomycin D and cyclophosphamide (6). However, mortality rates remain high in case of recurrences and metastatic disease. Chemotherapy resistance and the failure of RMS cells to undergo apoptosis often occurs during disease progression (7). Therefore, new innovative approaches targeting specific signalling pathways are urgently needed.

The hedgehog $(\mathrm{Hh})$ pathway is involved in development, tissue regeneration but also several kinds of cancer including basal cell carcinoma, medulloblastoma, osteosarcoma, Ewing sarcoma and RMS (8-11). Ligand-dependent activation of Hh signalling occurs via Patched 1 (PTCH1) and Smoothened (SMO) leading to activation of the downstream transcription factors of the glioma-associated oncogene family GLI1, GLI2 and GLI3. All GLI proteins have transcriptional activator 
functions regulated by activation of Hh signalling. In absence of Hh pathway activation C-terminally truncated GLI2 and GLI3 proteins serve as transcriptional repressors (12). GLI1 is a direct transcriptional target of Hh signalling and its function is regulated by abundance (13) of posttranslational modifications $(12,13)$. However, especially in sarcoma aberrant, ligand-independent GLI1 activity has been observed (14-16).

Several SMO inhibitors have been developed and are in different phases of clinical validation $(17,18)$. These inhibitors do not prevent downstream pathway activation by overexpression and constitutive activation of GLI transcription factors. Therefore, direct targeting of GLI seems to be a more promising therapeutic approach (13).

In the present study, we determined whether the Hh pathway is active in RMS cell lines and contributes to cell proliferation and survival. To address this question, we compared the effects of different Hh inhibitors acting on SMO (cyclopamine, LDE225, itraconazole) $(19,20)$ or GLI (ATO, GANT61). Arsenic trioxide (ATO), which is FDA approved for the treatment of acute promyelocytic leukemia (APL) (21), prevents transcription of GLI1, GLI2 and PTCH1 in human osteosarcoma cell lines (11), blocks ciliary accumulation and reduces steady state levels of GLI2 after prolonged incubation in murine cells (22). GANT61, an experimentally used substance, reduces GLI1 mediated transcription in a luciferase based reporter screen (23) and induces apoptosis in a Ewing sarcoma cell line (16). We found especially ATO to be highly effective in reduction of viability and clonal growth as well as in apoptosis initiation in RMS cell lines of embryonal, alveolar and sclerosing, spindle cell subtype, whereas normal skeletal muscle cells were scarcely affected. Itraconazole was the only SMO inhibitor which increased ATO action in our experimental settings.

\section{Materials and methods}

Reagents. ATO (Trisenox, Pharmacy of University Hospital Tuebingen) was dissolved in purified water, GANT61 (Abcam, Cambridge, UK), itraconazole (Sigma-Aldrich, Taufkirchen, Germany) and LDE225 (Selleckchem, Munich, Germany) were dissolved in dimethyl sulfoxide (DMSO). Cyclopamine (Abcam) was dissolved in ethanol. For cell culture treatment stock solutions were further diluted in culture medium.

Cell lines and culture. RD cells were purchased from CLS Cell Lines Service GmbH (Eppelheim, Germany). RH-30 cells were obtained from ATCC (Manassas, VA, USA). CCA cells were kindly provided by Barbara Munz, Department of Sports Medicine, University Hospital Tuebingen. RUCH3 cells were kindly provided by Ingo Mueller, Clinic of Pediatric Hematology and Oncology, University Medical Center Hamburg Eppendorf. ZF (ARMS) and SRH (sclerosing, spindle cell RMS) were established and characterised at the University Children's Hospital Tuebingen. The patient (SRH cells) and the parents of the patient (ZF cells) had given their written informed consent to the scientific analysis and cell line establishment from tissue samples, the study of which was approved by the ethics committee of the University of Tuebingen. Normal skeletal muscle cells from adult donors
(SKMC) were purchased from PromoCell (Heidelberg, Germany). All cell lines were maintained in Dulbecco's modified Eagle's medium (DMEM) with GlutaMAX, $4.5 \mathrm{~g} / 1$ D-glucose (Gibco, Life Technologies, Darmstadt, Germany) supplemented with $10 \%$ FCS (Biochrom, Berlin, Germany) at $37^{\circ} \mathrm{C}$ in humidified atmosphere containing $5 \% \mathrm{CO}_{2}$.

RNA isolation and $q R T-P C R$. RNA was isolated using the RNeasy Mini kit (Qiagen, Hilden, Germany). One microgram of RNA was reversely transcribed using the innuSCRIPT reverse transcriptase (Analytik Jena, Jena, Germany). cDNA (50 ng) was analysed in duplicate reactions by quantitative RT-PCR (qRT-PCR) using gene-specific primers and $1 \mathrm{X}$ SYBR select master mix for CFX (Life Technologies $\mathrm{GmbH}$ ) in a total volume of $10 \mu \mathrm{l}$. qRT-PCR was carried out in a CFX96 realtime device (Bio-Rad, Munich, Germany) and was analysed using CFX Manager ${ }^{\mathrm{TM}}$ software (Bio-Rad). Relative expression levels were calculated as fold change compared to SKMC cells using the $\Delta \Delta \mathrm{Ct}\left(2^{-\Delta \Delta \mathrm{Ct}}\right)$ method with TATA box binding protein (TBP) as a reference gene. Hh pathway primers were used according to Laurendeau et al (24).

Cytotoxicity assay. The Cell Titer $96^{\circledR}$ AQueous One Solution Cell Proliferation (MTS) assay (Promega, Mannheim, Germany) was used to measure cell viability via redox enzyme activity, according to the protocol provided by the manufacturer. SRH, RD, CCA, RUCH3, RH-30, ZF and SKMC cells $\left(0.5-1.5 \times 10^{4}\right.$ cells/well) were grown in 96 -well plates. The day after seeding, the cells were incubated in the presence of ATO, GANT61, cyclopamine, LDE225 or itraconazole for another $96 \mathrm{~h}$ at $37^{\circ} \mathrm{C}$ in a humidified atmosphere of $5 \% \mathrm{CO}_{2}$ in air. At the end of the incubation period, $15 \mu \mathrm{l}$ MTS reagent was added to the wells, and the plate was incubated for $1.5 \mathrm{~h}$ protected from light. Absorbance was recorded at $490 \mathrm{~nm}$ with a reference wavelength of $630 \mathrm{~nm}$ using an EL 800 reader (BioTek, Winooski, VT, USA).

$I C_{50}$ determination. $\mathrm{IC}_{50}$ values of ATO, GANT61, cyclopamine and LDE225 were determined for the different cell lines by non-linear regression using GraphPad Prism V6.0 software.

Colony formation assay. RD, RH-30 and ZF cells were plated at a density of $0.5 \times 10^{3}$ cells/well, RUCH3 cells were plated at a density of $2.5 \times 10^{3}$ cells/well in a 6 -well plate and incubated with increasing concentrations of ATO, LDE225, itraconazole or inhibitor combinations for $72 \mathrm{~h}$. After 10 days subsequent growth in standard growth medium, cells were fixed using ice cold methanol for $15 \mathrm{~min}$, washed and stored in PBS. Visualisation of fixed cell colonies was achieved by incubating the cells with $0.5 \%$ (w/v) crystal violet for $30 \mathrm{~min}$. Excess crystal violet was removed by washing with PBS. Visible colonies, consisting of $\geq 50$ cells, were counted. The colony formation rate was determined: (number of colonies/ number of plated cells) x 100 .

Spheroid assay. For generation of 3D spheroids $0.5 \times 10^{4}$ cells of the RMS cell lines RD, RH-30 and ZF were seeded in ultralow-attachment, U-bottom 96-well plates (Thermo Scientific, Rochester, NY, USA). After 96 h spheroid formation was 
documented by micrographs and Hh inhibitors were added to the culture medium as indicated. Six days later a second documentation by micrographs was performed.

PathScan ${ }^{\circledR}$ sandwich ELISA assay. RD cells $\left(0.5 \times 10^{6}\right)$ were incubated with inhibitor concentrations indicated for $48 \mathrm{~h}$ in 6-well plates and the PathScan ${ }^{\circledR}$ ELISA (Cell Signaling Technology, Leiden, The Netherlands) specific for phosphop53 (Ser15) \#7365C, total p53 \#7370C, phospho-Bad (Ser112) \#7182C, total Bad \#7162C was carried out according to the manufacturer's instructions.

Western blot analysis. The SRH, RD, CCA, RUCH3, RH-30 and $\mathrm{ZF}$ cells (each at $1.5 \times 10^{5}$ cells/well) and the SKMC cells (at $2.5 \times 10^{5}$ cells/well) were incubated in 6 -well plates with inhibitor concentrations indicated for $48 \mathrm{~h}$. For analysis, cells were washed with PBS and lysed in protein lysis buffer $(40 \mathrm{mM}$ Tris/ $\mathrm{HCl} \mathrm{pH}$ 7.4, 300 mM NaCl, 2 mM EDTA, 20\% glycerol, $2 \%$ Triton $\mathrm{X}-100)$ supplemented with proteinase inhibitor at $4^{\circ} \mathrm{C}$. Insoluble material was removed by centrifugation. The protein concentration in the supernatant was determined by Bradford protein assay. Protein samples $(40 \mu \mathrm{g})$ were separated by $10 \%$ SDS-PAGE and transferred to a hydrophobic polyvinylidene difluoride (PVDF) membrane (Immobilon-P; Merck KGaA, Darmstadt, Germany). After blocking with 5\% powdered milk (Carl Roth, Karlsruhe, Germany) in TBS-T, membranes were incubated with primary antibodies [GLI1 rabbit $\mathrm{mAb} \# 2533$, $\beta$-tubulin (9F3) rabbit $\mathrm{mAb} \# 2128$, cleaved caspase 3 (5A1E) rabbit $\mathrm{mAb} \# 9664$, anti-cleaved PARP (DE64E10) rabbit $\mathrm{mAb}$ \#5625, full length caspase 3 (8G10) rabbit $\mathrm{mAb} \# 9665$, all 1:1,000, Cell Signaling Technology; GLI2 (H300) rabbit pAb, 1:200, sc-28674, Santa Cruz Biotechnology Inc., Dallas, TX, USA; cell cycle (pCdk/pHH3/ actin) WB cocktail, 1:250, ab136810, Abcam] with gentle shaking overnight at $4^{\circ} \mathrm{C}$ according to the manufacturer's protocols. Membranes were washed three times with TBS-T. Secondary antibody (horseradish peroxidase-conjugated anti-rabbit pAb, 1:20,000, Jackson Immuno Research, West Grove, PA, USA) was added for $2 \mathrm{~h}$, and the membranes were washed another three times with TBS-T. Proteins were detected using ECL Western Blotting Substrate (Thermo Scientific, Waltham, MA, USA) with membranes exposed to Amersham Hyperfilm ECL (GEHealthcare, Pittsburgh, PA, USA). A pre-stained protein ladder (PageRuler Plus; Thermo Scientific) was used for determination of molecular weights. ImageJ was utilised for western blot quantification.

Flow cytometry. Membrane integrity as indicator for cell death was determined using the fixable viability dye eFluor ${ }^{\circledR} 450$ (eBioscience, San Diego, CA, USA). The SRH, RD, CCA, RUCH3, RH-30, ZF and SKMC cells (each at $2.5 \times 10^{5}$ cells/ well) were incubated with inhibitor concentrations indicated for $72 \mathrm{~h}$, washed with PBS, detached with $1 \%$ trypsin, and stained for $30 \mathrm{~min}$ at $4^{\circ} \mathrm{C}$ in the dark. Cells were washed with PBS and fixed with $0.5 \%$ formaldehyde diluted in PBS before being resuspended in FACS buffer (PBS containing 2\% FCS, 2 mM EDTA). Flow cytometric analysis was performed on an LSRII flow cytometer (Becton-Dickinson, Franklin Lakes, NJ, USA) using FlowJo Software (Tree Star Inc., Ashland, OR, USA) for data evaluation.
Statistical analysis. All statistical tests were performed using GraphPad Prism V6.0 or V5.0 software and p $<0.05$ was considered as statistically significant.

\section{Results}

Overexpression of hedgehog pathway genes in rhabdomyosarcoma. Hedgehog pathway gene expression was determined in six human RMS cell lines compared to SKMC (Fig. 1A). Quantitative real-time PCR revealed that GLI1 expression was upregulated in all RMS cell lines examined. Expression levels in SRH mostly resembled SKMC, whereas higher GLI1 expression levels were detected in the ERMS cell lines RD, CCA and RUCH3. The ARMS cell line ZF showed a strong GLI1 mRNA overexpression, while GLI1 was excessively upregulated in RH-30 cells, which contain a gene amplification (25). GLI2 expression in SRH and ZF cells was reduced compared to primary skeletal muscle cells. All other RMS cell lines exhibited a low to moderate overexpression of GLI2 mRNA. GLI3 expression was reduced in RH-30 cells compared to SKMC but moderately elevated in SRH, RD and ZF. High GLI3 mRNA expression was found in CCA and RUCH3. SMO mRNA levels of SRH and RD cells corresponded to SKMC, whereas, higher expression was found in all other RMS cell lines. The Hh receptor PTCH1 was slightly overexpressed in SRH and RUCH3. Stronger expression could be found in CCA, RH-30, ZF and RD cells. PTCH2 expression, on the contrary, was reduced in SRH and RUCH3 cells compared to SKMC, while it was slightly upregulated in CCA, RH-30, ZF and RD. Western blot analysis confirmed the expression of GLI1 protein in RMS cell lines and SKMC (Fig. 1B) with highest protein levels in RH-30 cells. However, depending on the cell line different variants of GLI1 dominated. In addition to the $160 \mathrm{kDa}$ form, in all RMS cell lines other splice variants (100-130 kDa) could be detected. Moreover, smaller bands probably corresponding to GLI1 degradation products appeared. For quantification all GLI1 signals $>100 \mathrm{kDa}$ were considered and normalised to tubulin expression. The graph shows the expression relative to SKMC. GLI2 full length protein expression (100-170 kDa) was reduced in $\mathrm{ZF}, \mathrm{SRH}, \mathrm{CCA}$ and $\mathrm{RUCH} 3$ cells compared to SKMC, while it was elevated in RD and RH-30 RMS cell lines (Fig. 1C). Additionally, all RMS cell lines comprised the GLI2 repressor form of $\sim 80 \mathrm{kDa}$. With the exception of RUCH3 and ZF cells, expression of the GLI2 repressor protein was increased in the RMS cells compared to SKMC. Remarkably, a prominent $55 \mathrm{kDa}$ band appeared exclusively in the primary skeletal muscle cells. These results show that the Hh pathway components are actively expressed in different RMS cell lines irrespective of their association to the embryonal, alveolar or sclerosing, spindle cell subtype.

Hedgehog pathway inhibition reduces viability of human RMS cell lines. We performed MTS viability assays to determine $\mathrm{IC}_{50}$ values of ATO, GANT61, cyclopamine, LDE225 and itraconazole in six RMS cell lines and SKMC (Table I). While viability of SKMC was still $77.5 \%$ after $96 \mathrm{~h}$ of incubation with $10 \mu \mathrm{M}$ ATO, the $\mathrm{IC}_{50}$ values for all RMS cell lines ranged from $1.31 \mu \mathrm{M}$ in $\mathrm{RH}-30$ to $3.67 \mu \mathrm{M}$ in SRH. This emphasises the strong and highly selective impact of ATO on RMS cells. 
A
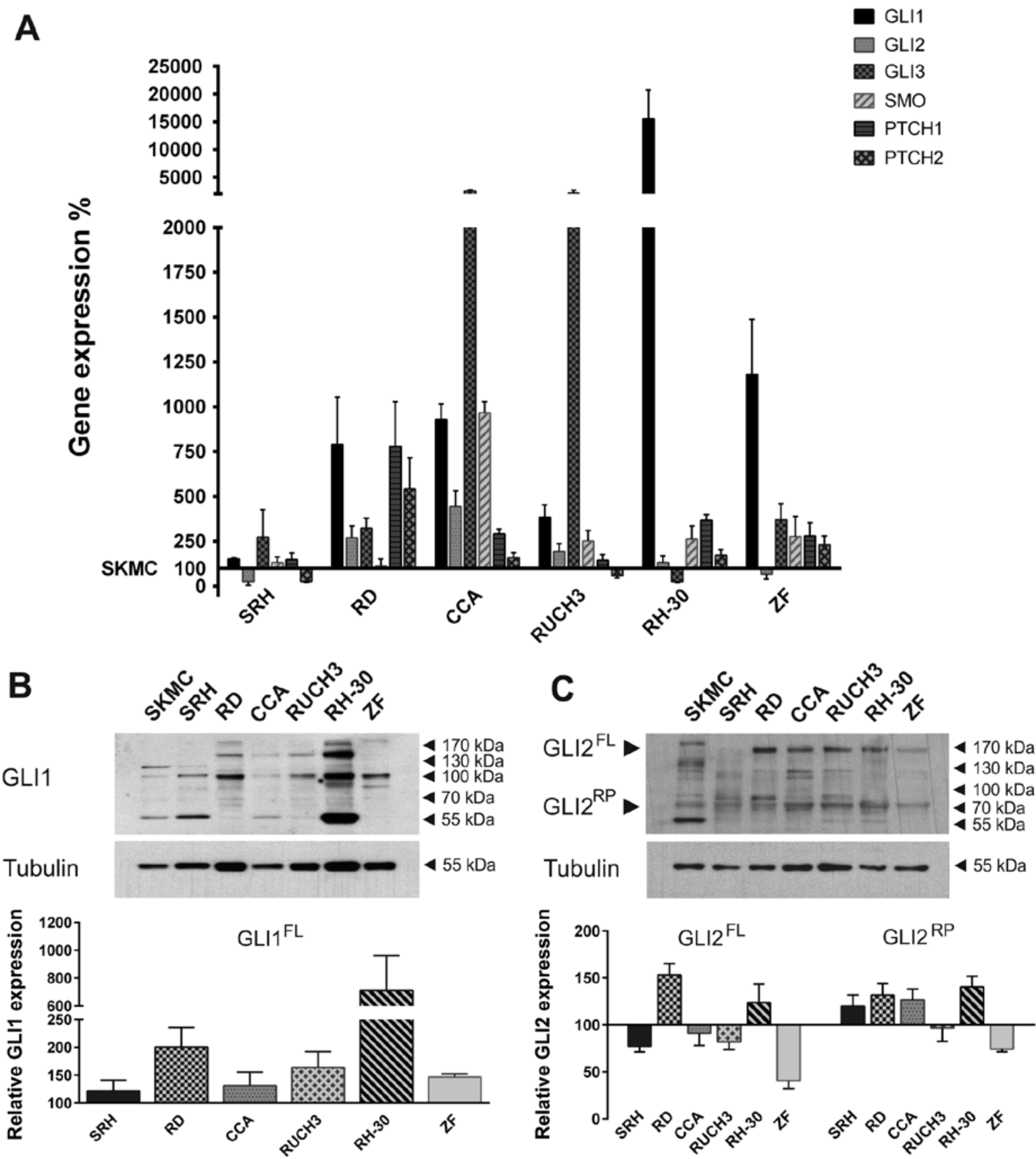

Figure 1. Human RMS cell lines express Hh pathway genes. (A) Total RNA was extracted from six RMS cell lines and SKMC. Quantitative RT-PCR was performed for the genes GLI1, GLI2, GLI3, SMO, PTCH1 and PTCH2 in quadruplicate and normalised to the housekeeping gene TBP. Expression levels relative to human skeletal muscle cells (SKMC) are shown. Error bars indicate the standard deviation. (B and C) Protein was extracted from six RMS cell lines and SKMC and western blot analysis was performed for GLI1 (B) or GLI2 (C) expression, tubulin was used for loading control. Signals of three independent experiments were quantified. The graphs show the mean values and standard deviations of GLI1 full length (GLI1 ${ }^{\mathrm{FL}}$ ) protein (B) or GLI2 full length (GLI2 ${ }^{\mathrm{FL}}$ ) and repressor (GLI2 ${ }^{\mathrm{RP}}$ ) protein expression (C) compared to SKMC.

The second GLI inhibitor GANT61, on the contrary, was also efficient in all RMS cell lines examined. However, primary skeletal muscle cells were more strongly impaired in their viability than RUCH3 cells and nearly to the same extent compared to RH-30 and SRH cells. Also the SMO inhibitor cyclopamine showed a poor selectivity and in case of the cell line RUCH3 no effect, while sensitivity of SRH and RD cells was still detectable, although lower than in SKMC. Only ZF cells were strongly compromised by cyclopamine. LDE225, the more selective and stable derivative of cyclopamine, which is already used in clinical studies (17), had no impact on SKMC at a dose of $35 \mu \mathrm{M}$. However, SRH, RUCH3 and RH-30 cell viability was also not affected and $\mathrm{IC}_{50}$ values for $\mathrm{CCA}$ and $\mathrm{ZF}$ were significantly higher compared to cyclopamine. Only RD cells showed a comparable dose response. Up to the concentration of $20 \mu \mathrm{M}$ itraconazole affected none of the cell lines sufficiently to determine $\mathrm{IC}_{50}$ values. However, in RUCH3 and RH-30 cells viability was slightly reduced. Our results show that GANT61 and cyclopamine are unsuitable for selective tumour cell treatment. Nevertheless, at the doses applied in 
Table I. Hh pathway inhibition reduces viability in human RMS cell lines.

\begin{tabular}{|c|c|c|}
\hline Inhibitor & Cell line & $\mathrm{IC}_{50}(\mu \mathrm{M})$ \\
\hline \multirow[t]{7}{*}{ ATO } & SKMC & $>10$ \\
\hline & SRH & 3.67 \\
\hline & $\mathrm{RD}$ & 1.51 \\
\hline & $\mathrm{CCA}$ & 2.09 \\
\hline & RUCH3 & 2.64 \\
\hline & RH-30 & 1.31 \\
\hline & $\mathrm{ZF}$ & 2.00 \\
\hline \multirow[t]{7}{*}{ GANT61 } & SKMC & 14.92 \\
\hline & SRH & 13.32 \\
\hline & $\mathrm{RD}$ & 8.38 \\
\hline & $\mathrm{CCA}$ & 8.97 \\
\hline & RUCH3 & 16.92 \\
\hline & RH-30 & 13.13 \\
\hline & $\mathrm{ZF}$ & 9.36 \\
\hline \multirow[t]{7}{*}{ Cyclopamine } & SKMC & 13.49 \\
\hline & SRH & 15.96 \\
\hline & $\mathrm{RD}$ & 15.71 \\
\hline & $\mathrm{CCA}$ & 9.96 \\
\hline & RUCH3 & $>35$ \\
\hline & RH-30 & 11.93 \\
\hline & $\mathrm{ZF}$ & 4.08 \\
\hline \multirow[t]{7}{*}{ LDE225 } & SKMC & $>35$ \\
\hline & SRH & $>35$ \\
\hline & $\mathrm{RD}$ & 15.57 \\
\hline & $\mathrm{CCA}$ & 13.00 \\
\hline & RUCH3 & $>35$ \\
\hline & RH-30 & $>25$ \\
\hline & $\mathrm{ZF}$ & 6.65 \\
\hline \multirow[t]{7}{*}{ Itraconazole } & SKMC & $>20$ \\
\hline & SRH & $>20$ \\
\hline & $\mathrm{RD}$ & $>20$ \\
\hline & $\mathrm{CCA}$ & $>20$ \\
\hline & RUCH3 & $>20$ \\
\hline & RH-30 & $>20$ \\
\hline & $\mathrm{ZF}$ & $>20$ \\
\hline
\end{tabular}

MTS assay was performed four days after treatment with ATO, GANT61, cyclopamine, LDE225 or itraconazole in six RMS cell lines and primary skeletal muscle cells (SKMC) in quadruplicate. Mock-treated control was set to $100 \%$ viability. $\mathrm{IC}_{50}$ values for the Hh pathway inhibitors were determined by non-linear regression of MTS results using GraphPad Prism 6.

viability assays LDE225 and itraconazole were largely inefficient. This emphasises ATO as the most promising candidate substance for Hh pathway inhibition.
ATO in combination with itraconazole impairs colony formation of RMS cell lines. Although itraconazole lacks significant effects on cell viability we analysed both ATO and itraconazole in single and combined treatment in clonogenic assays performed with RD, RUCH3, RH-30 and ZF cells (Fig. 2). The cell lines SRH and CCA did not to form colonies from single cells and were therefore excluded from this experiment. The addition of $1 \mu \mathrm{M}$ ATO for $72 \mathrm{~h}$ was sufficient to significantly impair colony formation in RD, RUCH3 RH-30 and ZF cells compared to mock-treated control, whereas $2 \mu \mathrm{M}$ largely abolished colony growth in all cell lines except ZF (Fig. 2B). Moreover, the size of the persisting colonies was reduced (Fig. 2A). Compared to the results of the viability assays, resistance of ZF cells to ATO was higher in the clonogenic assay. The colony formation rate of RUCH3 cells was generally low in this experimental setting. Although itraconazole had no impact on cell viability in the MTS assays, a significant reduction of colony numbers could be detected after addition of $5 \mu \mathrm{M}$ itraconazole in RD, RH-30 and ZF cells (Fig. 2B). Combination of $1 \mu \mathrm{M}$ ATO with $5 \mu \mathrm{M}$ itraconazole substantially blocked colony formation in RH-30 cells, whereas some microcolonies remained in RD, RUCH3 and ZF cells. Elevation of the ATO dose to $2 \mu \mathrm{M}$ suppressed colony growth in three of the RMS cell lines. Only ZF cells still formed a small number of microcolonies after combined treatment with $2 \mu \mathrm{M}$ ATO and $5 \mu \mathrm{M}$ itraconazole. Interestingly, this additive effect was less pronounced using combined treatment of ATO with LDE225 (data not shown). However, a single dose of $15 \mu \mathrm{M}$ LDE225 was sufficient to stop colony formation in RD, RUCH3, RH-30 and ZF cells (data not shown). Conspicuously, proliferation of RUCH3 cells was inhibited by LDE225 during the longer experimental setting of the colony formation assay compared with the lack of viability restriction during the $96 \mathrm{~h}$ of MTS assay.

ATO reduces RMS cell growth in $3 D$ spheroid culture. $3 \mathrm{D}$ spheroid cultures resemble tumour formation in vivo exhibiting gradients in nutrition and oxygen availability but also in penetration by cytotoxic substances. As ATO but also a combination of ATO and itraconazole were effective in viability reduction and inhibition of colony formation, these $\mathrm{Hh}$ inhibitors were applied in 3D spheroid cultures of RD, RH-30 and ZF cells. The RMS cell lines SRH, CCA and RUCH3 refused to form stable 3D cultures and had to be excluded from this experiment. As the representative micrographs of Fig. 3 show, there was a dose-dependent reduction of spheroid growth by ATO in ZF cells with $5 \mu \mathrm{M}$ ATO completely blocking the increase in size. In RD cells already $2 \mu \mathrm{M}$ ATO were sufficient to completely inhibit spheroid growth. RH-30 cells were less sensitive in 3D culture and ATO could not reduce spheroid growth. Itraconazole reduced growth of $\mathrm{ZF}$ spheroids, however much less compared to ATO, whereas RD and RH-30 spheroids were not compromised. Growth inhibition of ZF spheroids was enhanced by the combination of $2 \mu \mathrm{M}$ ATO and $5 \mu \mathrm{M}$ itraconazole compared to single doses. However, it was not as effective as $5 \mu \mathrm{M}$ ATO. In RD cells the impact of the inhibitor combination was comparable to ATO single treatment. Interestingly, an additive effect could be documented in RH-30 cells, the spheroid growth was not fully prevented but reduced compared to single treatments. 


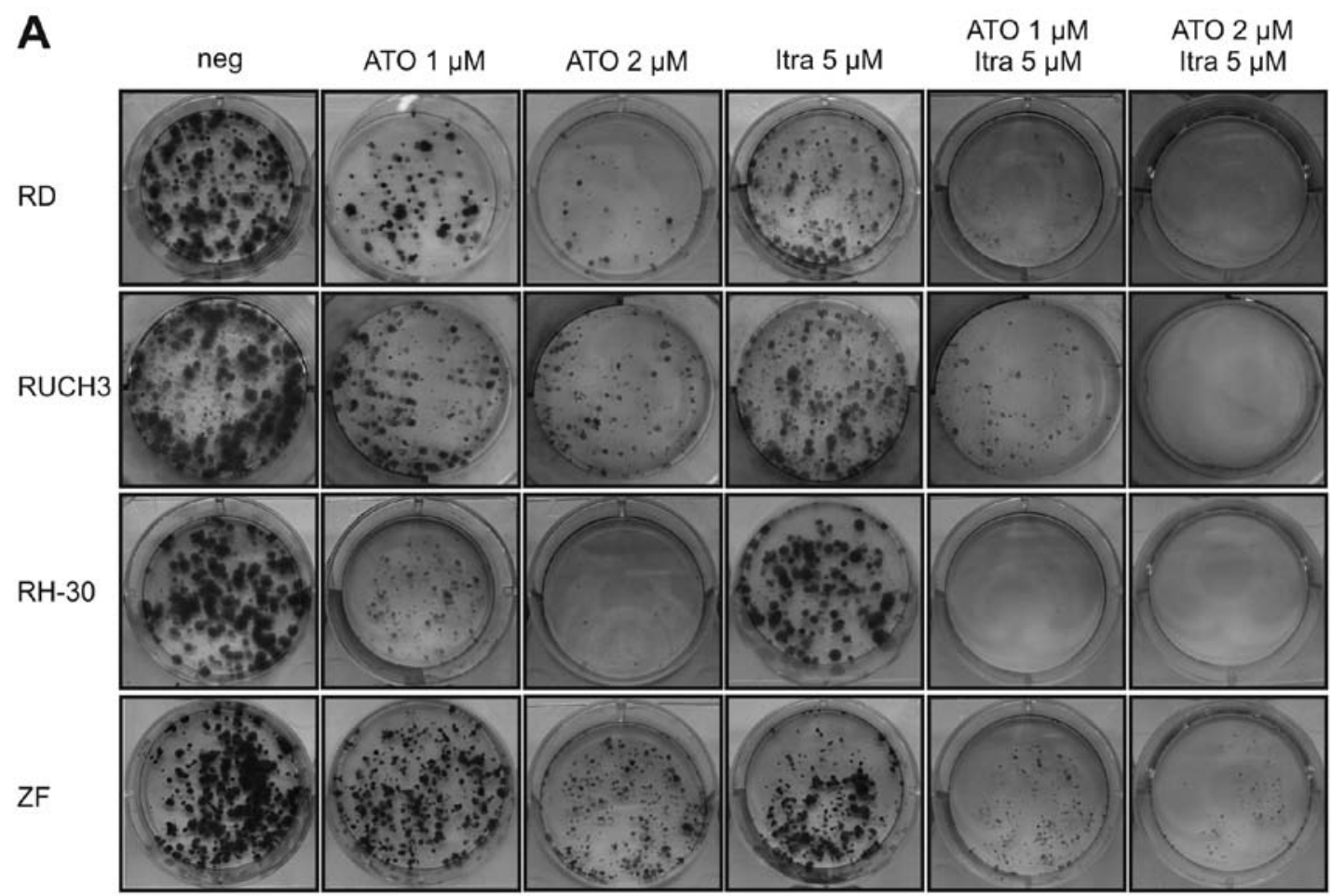

B

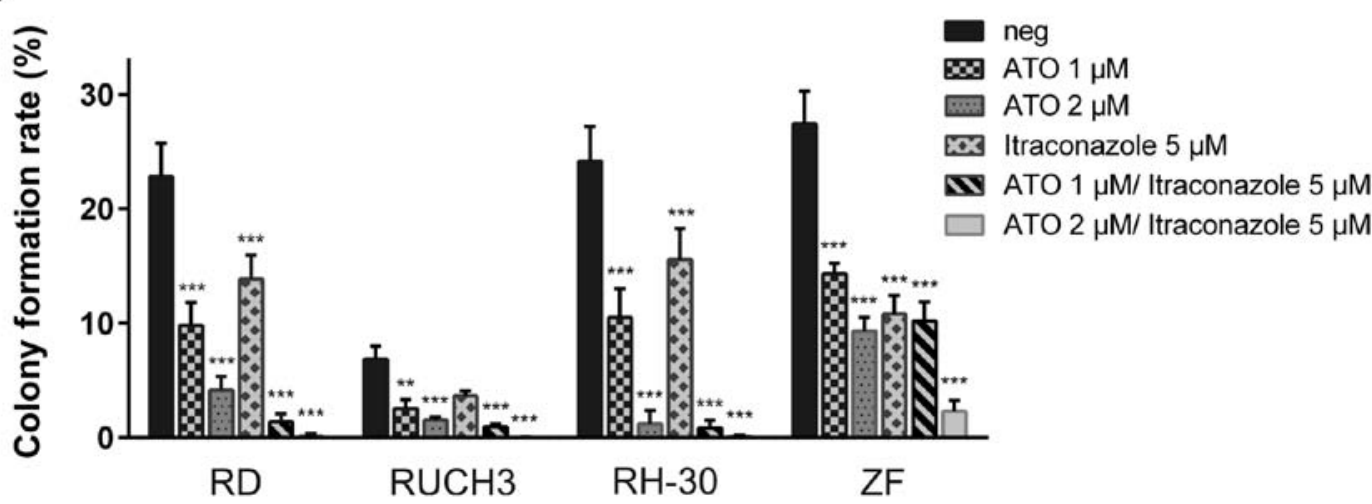

Figure 2. ATO in combination with itraconazole impairs colony formation of RMS cell lines. The RD, RH-30 and ZF cells (each at $0.5 \times 10^{3}$ cells/well) or the RUCH3 cells (at $2.5 \times 10^{3}$ cells/well) were seeded in 6-well plates and incubated with the ATO and itraconazole (Itra) concentrations indicated for $72 \mathrm{~h}$. Subsequently, cells were incubated in normal culture medium for another ten days. Visualisation of fixed cell colonies was achieved by incubating the cells with $0.5 \%(\mathrm{w} / \mathrm{v})$ crystal violet. Representative images for each cell line are shown (A). Colonies of four independent experiments were counted. The graph indicates the mean colony formation rates with standard deviations $\left({ }^{* *} \mathrm{p} \leq 0.01,{ }^{* * *} \mathrm{p} \leq 0.001\right.$ compared to mock-treated control) (B).

Hedgehog pathway inhibition induces cell death. As cancer treatment affords effective killing of resident tumour cells and not only a transient growth inhibition, we performed flow cytometry analysis to detect incorporation of the fixable viability dye eFluor ${ }^{\circledR} 450$. The dye is excluded from cells with intact membranes, therefore apoptotic or necrotic cells with membrane degradation can be quantified using this method. Six RMS cell lines and SKMC were incubated with ATO, GANT61, cyclopamine, LDE225 or itraconazole for three days before assessment of cell death (Fig. 4). Treatment with $2 \mu \mathrm{M}$ ATO already induced significant dye incorporation in the RMS cell lines RD, CCA and RH-30. Using $5 \mu \mathrm{M}$ ATO cell death increased to $65 \%$ (SRH), $86 \%$ (RD), $81 \%$ (CCA), $49 \%$ (RUCH3) or 82\% (RH-30). ZF cells showed only a small proportion of dead cells $(9 \%)$, whereas $6 \%$ of SKMC were stained by the dye. The second GLI1 inhibitor
GANT61 was most effective in CCA cells at the low dose of $10 \mu \mathrm{M}$. Increasing the GANT61 concentration to $15 \mu \mathrm{M}$ led to $54 \%$ (SRH), $28 \%$ (RD), $77 \%$ (CCA), $42 \%$ (RUCH3) and 73\% (RH-30) dead cells. However, GANT61 also induced cell death in $16 \%$ of the SKMC, which was more than in the resistant ZF cells (10\% dead cells). Moreover, the histograms show a less complete shift of the cell populations after addition of GANT61 compared to ATO (Fig. 4A). Using SMO inhibitors induction of cell death was less efficient (Fig. 4B). At a concentration of $10 \mu \mathrm{M}$ itraconazole only CCA (17\%), RUCH3 (21\%) and RH-30 cells (34\%) showed significant cell death induction. Cyclopamine $(15 \mu \mathrm{M})$ induced $17 \%$ (SRH), $23 \%$ (RD), $30 \%$ (CCA), $19 \%$ (RUCH3), 13\% (RH-30) and 12\% (ZF) cell death, respectively. Interestingly, membrane integrity of SKMC was not affected at all by this drug concentration. The impact of the cyclopamine derivative LDE225 was still 


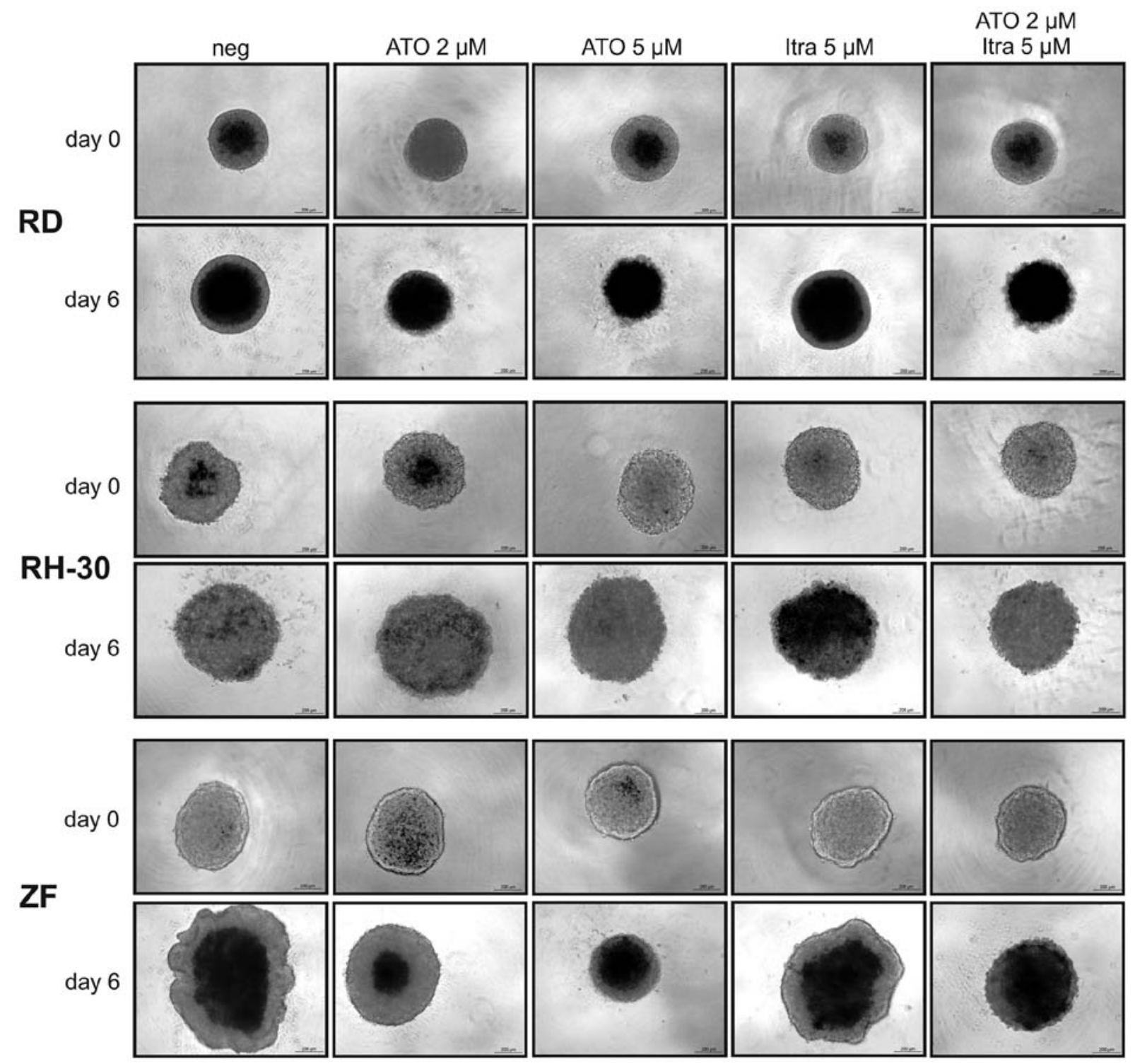

Figure 3. ATO and a combination of ATO and itraconazole reduce RMS cell growth in 3D-spheroid cultures. The RD, RH-30 or ZF cells (each at $0.5 \times 10^{4}$ cells/ well) were plated in non-adherent, U-bottom 96 -well plates. After four days spheroid formation was documented with the microscope (day 0). Spheroids were incubated with the ATO and itraconazole (Itra) concentrations indicated for another six days whereupon a second micrograph was taken (day 6). Representative micrographs of three independent experiments are shown.

lower with maximum cell death induction of $15 \%(\mathrm{SRH}), 16 \%$ (CCA) and $15 \%(\mathrm{ZF})$ at the concentration of $15 \mu \mathrm{M}$. Again, SKMC showed $<1 \%$ dye incorporation. These results indicate that Hh pathway inhibition at the level of GLI1 has explicit advantage over SMO inhibition. Even cyclopamine, showing a noticeable impact on viability of RMS cells and SKMC, was inefficient for induction of cell death.

ATO-dependent Hh pathway inhibition induces apoptosis in RMS cell lines. The viability dye eFluor ${ }^{\circledR} 450$ is not able to discriminate between necrotic and apoptotic cell death. In order to detect apoptosis induction after treatment with $5 \mu \mathrm{M}$ ATO western blot analysis was performed in all six RMS cell lines and SKMC (Fig. 5A). Apoptotic PARP cleavage, as indicated by the $89 \mathrm{kDa}$ fragment, was clearly induced by ATO in all RMS cell lines but not SKMC at the time of cell lysis. The reaction of RUCH3 cells was very distinct indicated by strong caspase 3 cleavage and nearly total tubulin degradation after two days (Fig. 5A and B). Due to global protein degradation the PARP band was comparably weak in these cells. Also RH-30 cells showed a strong response indicated by significant reduction of full length caspase 3 and tubulin. In this case the cleaved caspase 3 band already was very faint while cleaved PARP could be still detected in high amounts. Caspase 3 cleavage was also detected in RD and CCA cells, while SRH and ZF cells showed nearly no caspase 3 cleavage and no reduction of total caspase 3 , indicating an alternative way of PARP cleavage (Fig. 5A and B). To verify that ATO indeed targets the Hh pathway at the level of GLI1, which is an Hh target gene itself, we also analysed GLI1 protein expression after ATO incubation (Fig. 5A and C). A strong reduction of full length and modified GLI1 protein could be detected in RD, CCA, RUCH3 and RH-30 cells. Interestingly, in SRH cells the GLI1 protein accumulated after ATO treatment, while 

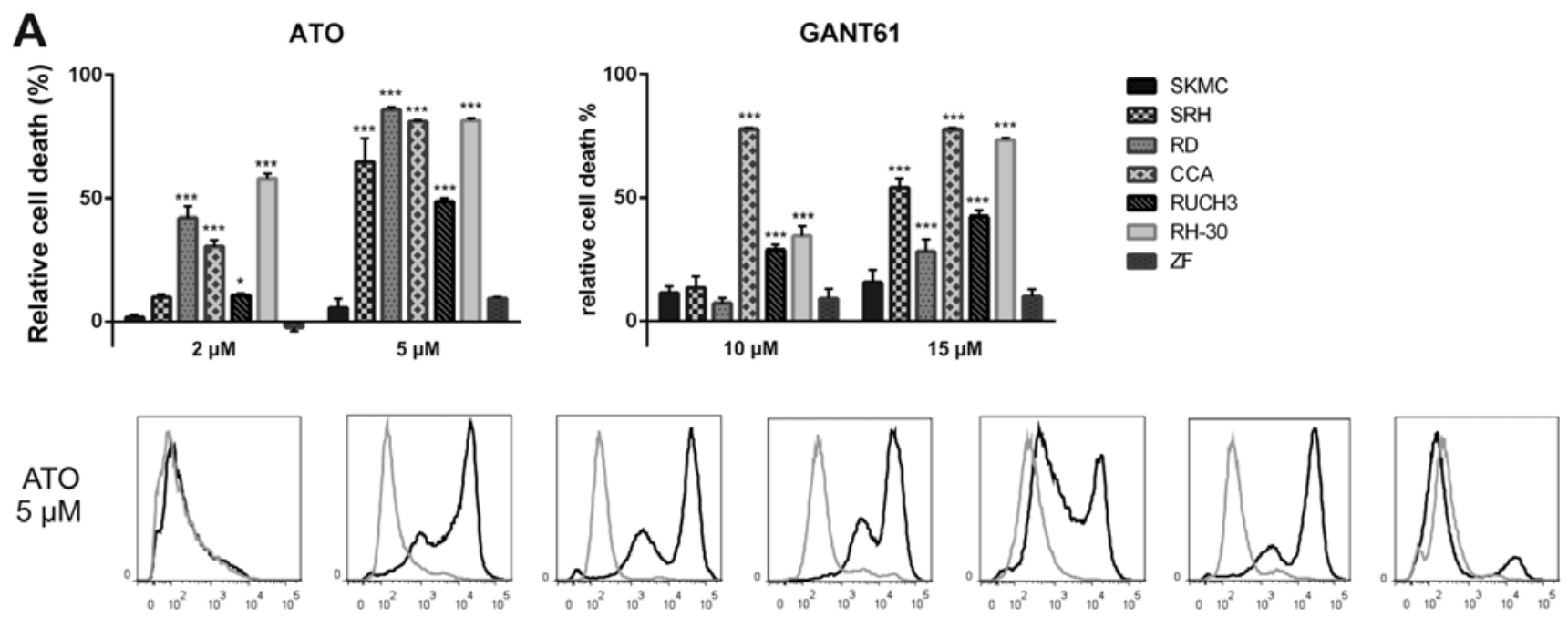

SKMC
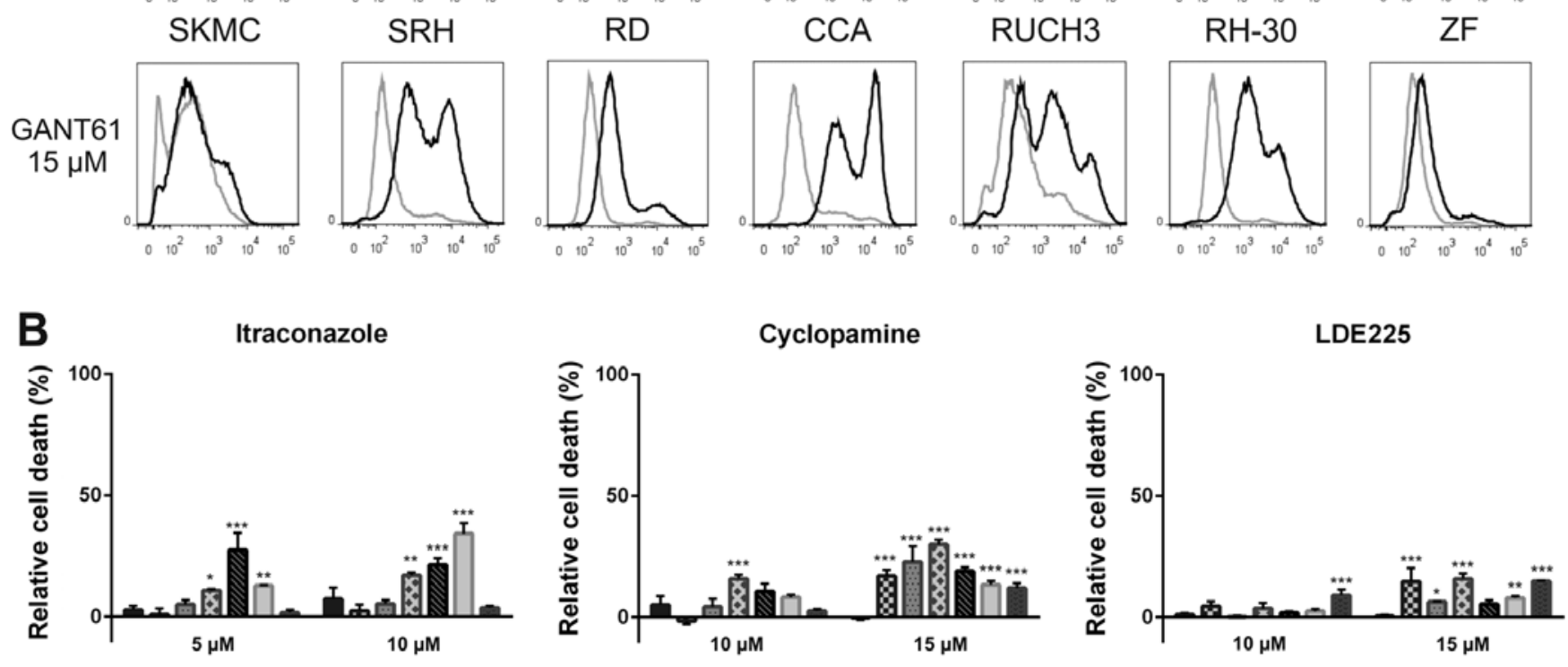

Figure 4. GLI inhibition induces cell death in RMS cell lines. (A) Incorporation of fixable viability dye eFluor ${ }^{\circledR} 450$ was analysed by flow cytometry three days after treatment with the GLI inhibitors ATO or GANT61 in six RMS cell lines and primary skeletal muscle cells in triplicate. Mock-treated control was set to zero \% cell death. Error bars indicate the standard deviation $\left({ }^{*} \mathrm{p} \leq 0.05,{ }^{* *} \mathrm{p} \leq 0.01,{ }^{* * *} \mathrm{p} \leq 0.001\right.$ relative to SKMC cell death). For treatment with $5 \mu \mathrm{M}$ ATO or $15 \mu \mathrm{M}$ GANT61 (black curves) and corresponding mock-treated controls (grey curves) representative FACS histogram plots are shown. (B) Incorporation of fixable viability dye eFluor ${ }^{\circledR} 450$ was analysed by flow cytometry three days after treatment with the SMO inhibitors cyclopamine, LDE225 or itraconazole in six RMS cell lines and primary skeletal muscle cells in triplicate. Mock-treated control was set to zero \% apoptosis. Error bars indicate the standard deviation $\left({ }^{*} \mathrm{p} \leq 0.05,{ }^{* *} \mathrm{p} \leq 0.01,{ }^{* * *} \mathrm{p} \leq 0.001\right.$ relative to SKMC cell death).

GLI1 protein was slightly reduced in ZF cells. SKMC showed no differences in PARP or caspase 3 cleavage. Compared to tubulin expression the amount of GLI1 was also slightly reduced in SKMC. These results indicate that ATO-dependent cell death induction in RMS cell lines involves the apoptotic pathway and is commonly linked to loss of full length GLI1. ZF cells which were highly resistant to ATO induced cell death exhibited no significant reduction of GLI1 abundance at the dose of $5 \mu \mathrm{M}$.

ATO induces cell cycle arrest in RMS cell lines. To elucidate the growth arrest and subsequent apoptosis after ATO treatment western blot analysis was performed in all six RMS cell lines and SKMC (Fig. 6A). Phosphorylation of CDK2 at Tyr15 indicates its inactivation at the G1/S transition, while Ser10 phosphorylation of histone $\mathrm{H} 3$ indicates a $\mathrm{G} 2 / \mathrm{M}$ cell cycle arrest $(26,27)$. Histone $\mathrm{H} 3$ phosphorylation was significantly increased in RD cells and was also elevated in CCA, RUCH3, RH-30 and ZF cells while actin expression was stable or reduced after ATO incubation, indicating a G2 arrest. Unfortunately, due to global protein degradation after $48 \mathrm{~h}$ of ATO incubation the impact on RUCH3 cell cycle was attenuated. In CCA cells a comparably weak histone $\mathrm{H} 3$ phosphorylation could be detected, but CDK2 Tyr15 phosphorylation was elevated after ATO treatment while actin was almost degraded, indicating a weak G1 arrest. Interestingly, the histone $\mathrm{H} 3$ phosphorylation could hardly be detected in SRH cells after ATO treatment while CDK2 Tyr15 phosphorylation decreased less distinct than the actin amount indicating a vague G1 arrest. SKMC cells showed only very weak $\mathrm{H} 3$ phosphorylation which was only slightly enhanced by ATO.

Apoptosis induction of RD cells is attenuated by inhibitory $B A D$ phosphorylation. Phosphorylation of p53 at Ser15 is 
A

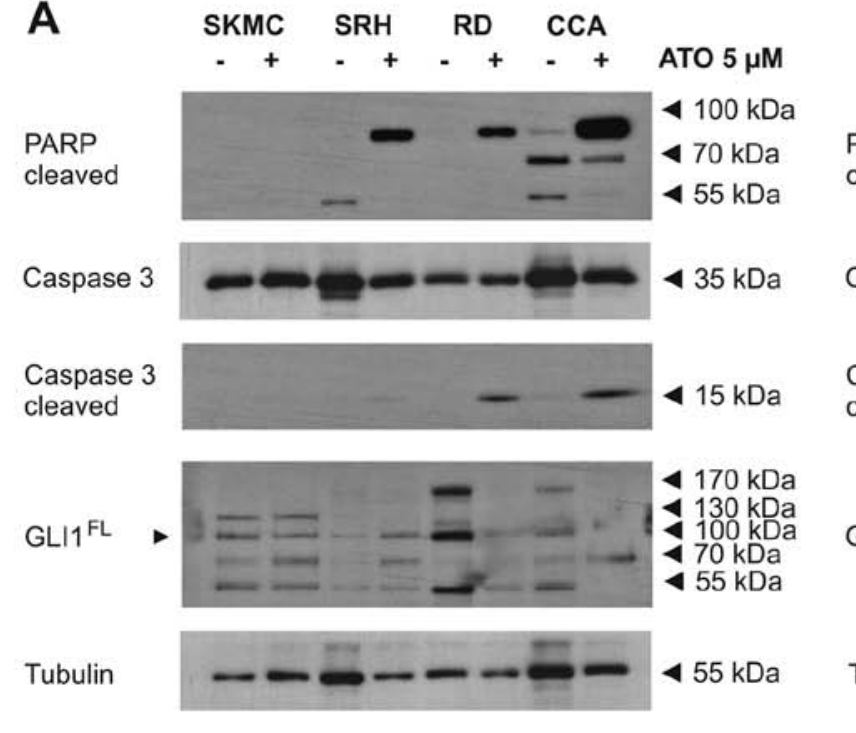

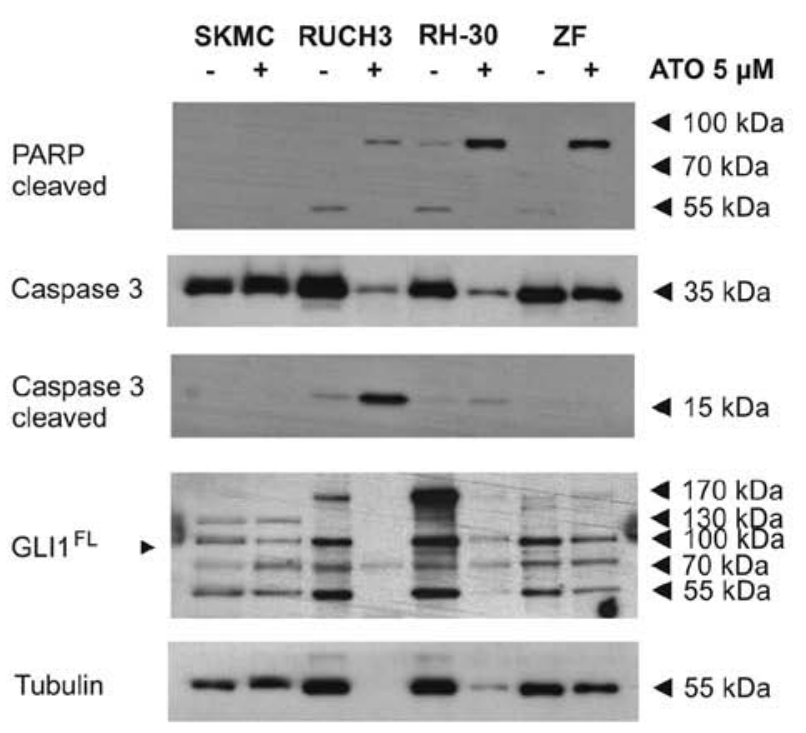

C

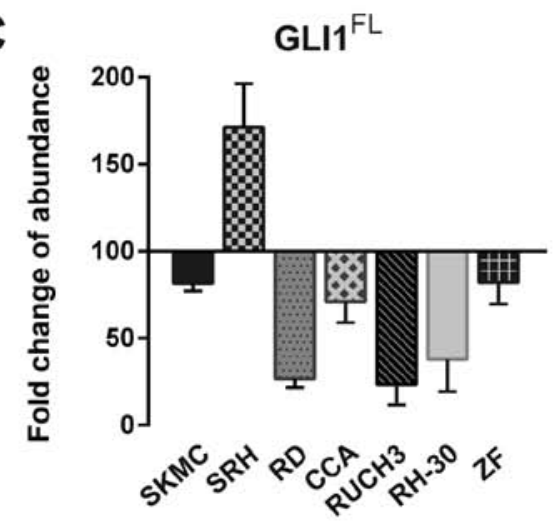

Figure 5. GLI inhibition induces apoptosis in RMS cell lines. Induction of apoptosis by $5 \mu \mathrm{M}$ ATO; six RMS cell lines and SKMC were incubated with ATO for two days. Cells were lysed and subjected to western blot analysis with antibodies against cleaved PARP, full length and cleaved caspase 3, GLI1 and tubulin as loading control (A). Signals of three independent experiments were quantified. The graphs show the mean values and standard deviations of caspase 3 and PARP cleavage (B) or full length GLI1 (GLI1 $\left.{ }^{\mathrm{FL}}\right)$ abundance $(\mathrm{C})$ after treatment with $5 \mu \mathrm{M}$ ATO compared to mock-treated control $\left({ }^{*} \mathrm{p} \leq 0.05,{ }^{* * *} \mathrm{p} \leq 0.001 \mathrm{compared}\right.$ to SKMC).

one of the first events of p53 modification occurring after metabolic stress or DNA damage (28). RD cells express the R248W mutant p53, while the second p53 allele is lost. This hot spot mutation causes at least partial inactivation of p53 function (29). Phosphorylation of the pro-apoptotic BAD protein at Ser112 inactivates its $B C L-X_{L}$ binding activity and sequesters it to the cytoplasm, preventing apoptotic cell death (30). Showing that ATO and a combination of itraconazole and ATO induced a growth arrest and apoptotic cell death in several RMS cell lines including RD, we chose RD cells for further elucidating the signalling pathways involved (Fig. 6B). Using a PathScan ${ }^{\circledR}$ ELISA we showed that p53 protein expression only slightly decreased after ATO and itraconazole treatment, while $2 \mu \mathrm{M}$ ATO was sufficient to induce a significant increase in p53 phosphorylation at Ser15, which was much weaker after treatment using a combination of $2 \mu \mathrm{M}$ ATO with $5 \mu \mathrm{M}$ itraconazole. However, itraconazole as single agent had no impact on p53 phosphorylation. While BAD protein expression was also slightly reduced after treatment with ATO or itraconazole, we found a massive Ser112 phosphorylation, especially after incubation with $2 \mu \mathrm{M}$ ATO, but also using the combination of $2 \mu \mathrm{M}$ ATO and $5 \mu \mathrm{M}$ itraconazole. In addition, itraconazole single treatment induced a distinct but comparably weaker Ser112 phosphorylation. These results clearly indicate that ATO induced p53 Ser15 phosphorylation, accompanied by a growth arrest. An effect which has to be discussed for the p53 mutated RD cells. Interestingly, the strong anti-apoptotic BAD Ser112 phosphorylation after ATO and itraconazole treatment should attenuate apoptosis induction in RD cells.

\section{Discussion}

The standard of care for treating RMS is a combination of multimodal chemotherapy and surgery (6). However, mortality rates remain high in case of recurrences and metastatic disease due to the development of drug resistance (7). Aberrant activation of the Hh signalling pathway has been found in several cancers including RMS (10). For this reason we investigated the impact of Hh pathway inhibition on RMS cell growth and survival. In our study we found all six RMS cell lines examined to actively express components of the Hh pathway with data of SRH cells mostly resembling primary skeletal muscle cells. Especially the GLI1 mRNA was overexpressed compared to SKMC with highest levels found in the ARMS 

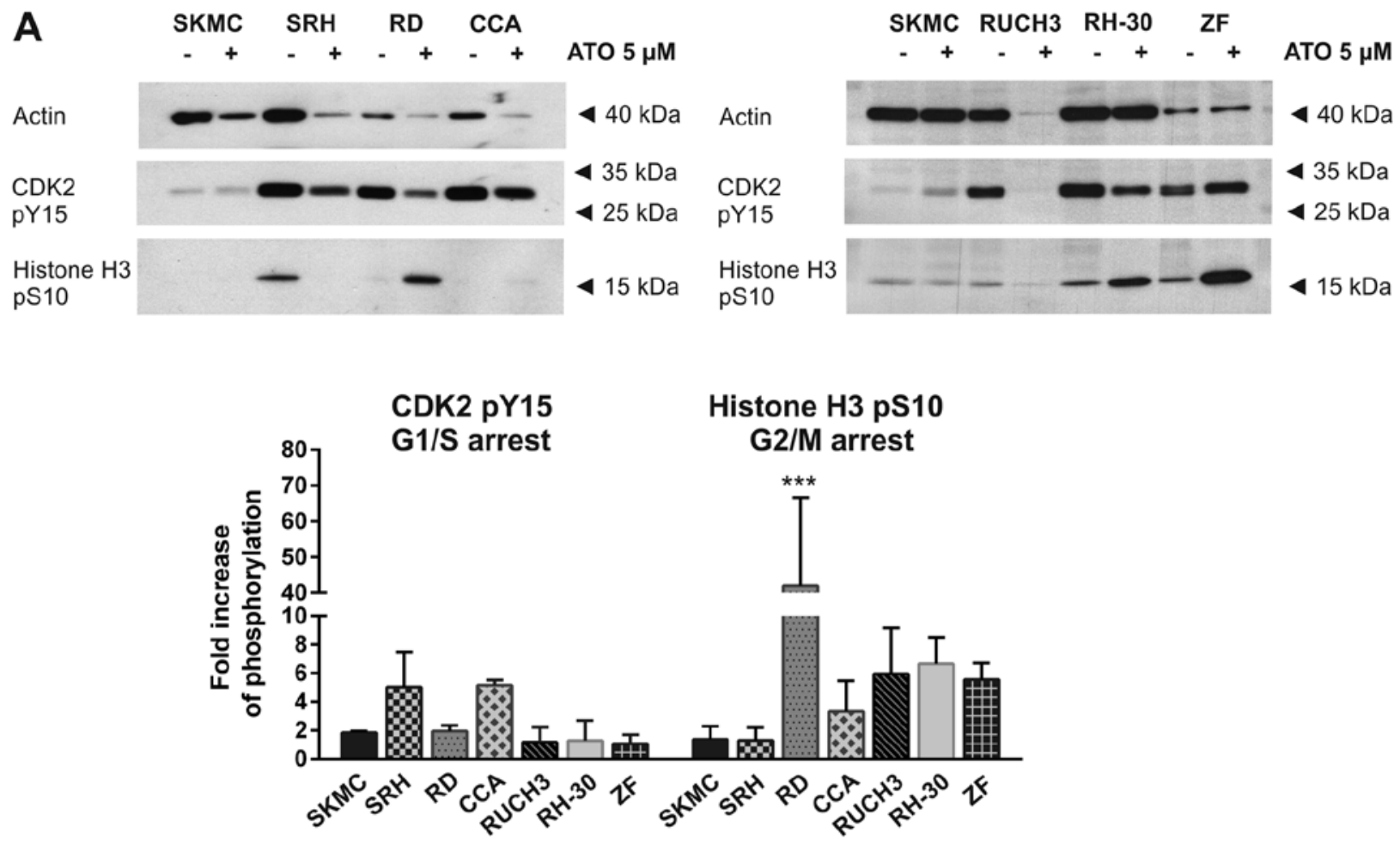

B

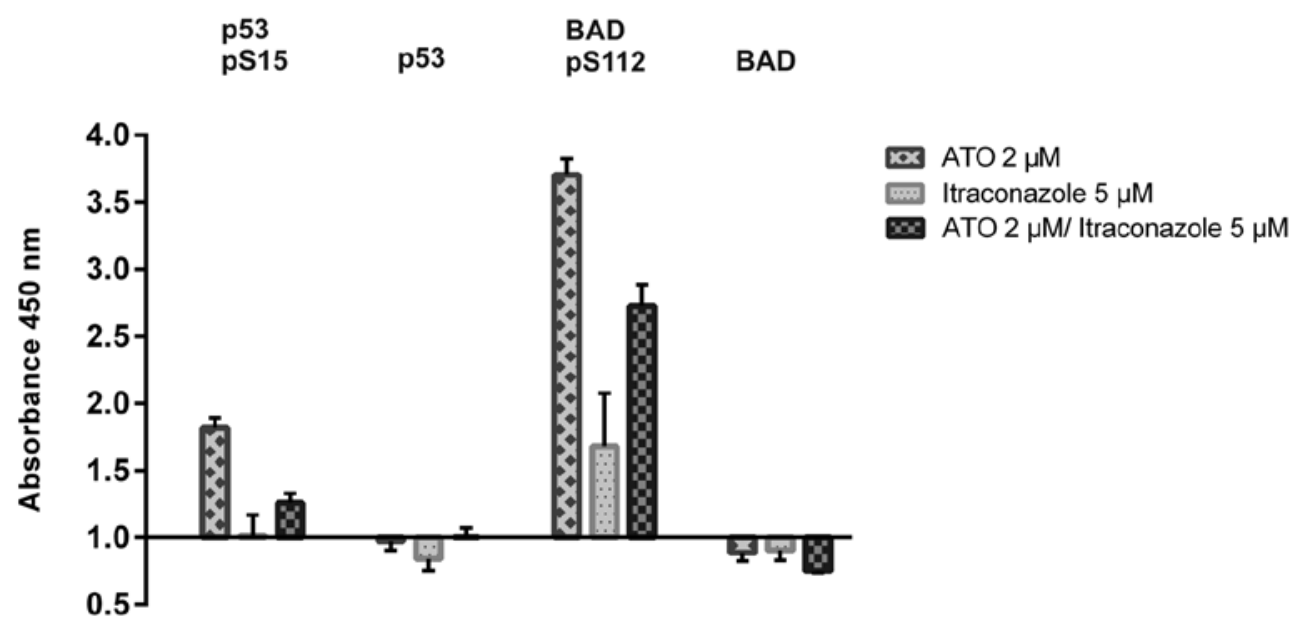

Figure 6. ATO treatment induces cell cycle arrest while apoptosis is extenuated by BAD phosphorylation. (A) Six RMS cell lines and SKMC were incubated with $5 \mu \mathrm{M}$ ATO for two days. Cells were lysed and subjected to western blot analysis. Phosphorylation of CDK2 Y15 (G1/S arrest) and phosphorylation of histone H3 S10 (G2/M arrest) of ATO and mock-treated cells were determined and compared to actin abundance. Signals of three independent experiments were quantified. The graph shows the mean values and standard deviations of phosphorylation after treatment with $5 \mu \mathrm{M}$ ATO compared to mock-treated control $\left(^{* * *} \mathrm{p} \leq 0.001\right.$ compared to SKMC). (B) PathScan ${ }^{\circledast}$ ELISA assay detecting $\mathrm{p} 53$ protein expression and $\mathrm{S} 15$ phosphorylation as well as BAD protein expression and S112 phosphorylation was performed in RD cells two days after addition of ATO and itraconazole in the concentrations indicated. Absorbance was measured at $450 \mathrm{~nm}$ and mock-treated cells were set to $100 \%$ protein expression, respectively phosphorylation. The experiment was performed in quadruplicate, error bars indicate the standard deviation.

cell lines RH-30 and ZF. RH-30 cells contain a GLI1 gene amplification (25) leading to massive expression of different GLI1 isoforms including the $160 \mathrm{kDa}$ full length and smaller variants. Interestingly, on protein level ZF cells showed only a moderate overexpression of a $100 \mathrm{kDa}$ isoform. Indeed, with the exception of CCA cells, we found the $100 \mathrm{kDa}$ isoform in all RMS cell lines to be more distinctly expressed compared to SKMC. GLI2 full length protein expression was significantly reduced in ZF cells compared to SKMC, whereas it was increased in RD and RH-30 RMS cell lines. In addition to the full length protein of $170 \mathrm{kDa}$, an $80 \mathrm{kDa}$ repressor form could be detected in all cells with diminished expression in ZF cells compared to SKMC. Conspicuously, the full length GLI2 protein in SKMC seems to be modified having a higher molecular weight compared to the RMS cell lines. On the other hand, only in SKMC there was a prominent $55 \mathrm{kDa}$ band, which was much smaller than the repressor form predicted (31), therefore most likely representing a degradation product. For inhibition of the Hh pathway two major targets can be addressed. Cyclopamine and its derivative LDE225 target SMO (18). In 
addition, itraconazole also inhibits SMO but uses a different binding site (20). More downstream in the Hh pathway the GLI inhibitors ATO and GANT61 prevent expression of Hh target genes $(22,23)$. Intriguingly, in RMS ligand-independent GLI1 activity has been observed, which may interfere with the efficiency of SMO inhibitors $(14,15,32)$. Other groups showed, that both GLI1 knockdown and a combination of GLI1 and GLI2 siRNA reduced RMS cell survival $(1,33)$.

In this study, we identified ATO as the most efficient and specific Hh inhibitor inducing growth arrest and apoptosis in a panel of RMS cell lines. ATO directly binds to GLI1 and GLI2, inhibiting their transcriptional activation capacity (34). Moreover, ATO promotes GLI2 degradation (35). We applied ATO doses of $2-5 \mu \mathrm{M}$, which correspond to plasma levels obtained in leukemia patients (36). We showed that ATO reduced viability, clonogenic survival and growth of $3 \mathrm{D}$ cultures in a dose-dependent manner in all RMS cell lines examined. In addition, RD, CCA, RUCH3 and RH-30 cells underwent apoptosis indicated by caspase 3 and PARP cleavage. However, our RMS cell lines comprise two recently established, low passage cell lines SRH and ZF, which exhibit almost no caspase 3 cleavage upon ATO treatment, while viability was significantly reduced. Interestingly, this lack of caspase 3-dependent apoptosis was accompanied by largely unchanged or indeed elevated GLI1 expression levels under ATO, indicating that the Hh pathway was still active in these cells under the dose of $5 \mu \mathrm{M}$ ATO. Whereas, the high dose of $5 \mu \mathrm{M}$ ATO was sufficient to induce cell death indicated by loss of membrane integrity in SRH cells, ZF cells remained almost completely resistant. Nevertheless, also ZF cells exhibited PARP cleavage upon ATO addition indicated by the $89 \mathrm{kDa}$ catalytic fragment. Indeed, both ZF and SRH cells were established from high grade RMS patients receiving multimodal chemotherapy prior to resection of the tumour, which may also contribute to general apoptosis resistance as described before (7). Analysis of histone 3 Ser10 phosphorylation revealed a clear G2/M arrest induced by $5 \mu \mathrm{M}$ ATO in RD, RH-30 and ZF cells. On the contrary, in SRH cells histone 3 Ser10 phosphorylation was not elevated upon ATO treatment, indicating an unaffected progression through $\mathrm{G} 2 / \mathrm{M}$ phase, while CDK2 Tyr15 phosphorylation was enhanced, suggesting a G1/S arrest. Also in CCA cells CDK2 Tyr15 phosphorylation remained high, while actin abundance decreased upon treatment with $5 \mu \mathrm{M}$ ATO, pointing to a G1 arrest. Actually, although a G2/M arrest is more commonly reported after ATO treatment, a G1 arrest was also found in myeloma cells. However, we can not consent to the statement that the ATO induced G2/M arrest and subsequent apoptosis is generally dependent on mutated p53 (37). We could prove that SRH cells comprise a p53 double mutant (data not shown) but these cells showed neither G2/M arrest nor caspase 3-dependent apoptosis after ATO treatment. On the other hand, CCA cells had a strong apoptotic caspase 3 and PARP cleavage but apparently only a weak G2/M arrest. In APL cell lines and primary APL blasts an ATO-dependent ERK1/2 activation seems to be implicated in an increased anti-apoptotic BAD Ser112 phosphorylation (38). In its phosphorylated stage BAD can no longer displace BAX from binding to $\mathrm{BCL}-2$ or $\mathrm{BCL}-\mathrm{X}_{\mathrm{L}}$ proteins, preventing the $\mathrm{BAX}$-dependent disruption of the mitochondrial membrane $(39,40)$. Furthermore, ATO was able to induce BAD Ser112 phosphorylation in RD cells. Regardless of this, a high number of dead cells could be detected after treatment of RD cells using $5 \mu \mathrm{M}$ ATO and apoptosis induction was proven by caspase 3 and PARP cleavage. Certainly, the intrinsic apoptotic pathway leading to mitochondrial disruption can be induced by ATO via downregulation of Bcl-2 expression in pulmonary adenocarcinoma cells (41) or hepatocellular carcinoma cells (42) or induction of the ER stress pathway (43), apparently overcoming the effect of BAD phosphorylation. Moreover, ATO was shown to induce the extrinsic apoptotic pathway via TRAIL and TRAIL receptor activation in myeloma cells $(37,44)$.

GANT61, the second GLI inhibitor used in this study, was a more effective cell death trigger compared to the SMO inhibitors cyclopamine, LDE225 and itraconazole in single application. Nevertheless, despite the efficacy of GANT61 in RMS cell lines as we and others could prove (33), it also compromised primary skeletal muscle cell viability and induced increased cell death.

As ATO and itraconazole are the only FDA approved substances tested, which are directly available for use in patients, we analysed the potential advantage of combination treatment. Actually, despite limited impact of itraconazole on RMS cell viability and cell death induction, the combination with ATO clearly reduced colony formation and spheroid size. Our results are in agreement with studies in mouse basal cell carcinoma and medulloblastoma allografts, where an additive effect of ATO and itraconazole could be demonstrated as well (35).

In conclusion, our data provide evidence that ATO is a promising substance for the treatment of RMS by directly targeting GLI transcription factors. Combination with itraconazole or chemotherapeutic drugs has the potential to enhance the treatment efficiency.

\section{References}

1. Tostar U, Toftgård R, Zaphiropoulos PG and Shimokawa T: Reduction of human embryonal rhabdomyosarcoma tumor growth by inhibition of the hedgehog signaling pathway. Genes Cancer 1: 941-951, 2010.

2. Egas-Bejar D and Huh WW: Rhabdomyosarcoma in adolescent and young adult patients: Current perspectives. Adolesc Health Med Ther 5: 115-125, 2014.

3. Ferrari A, Dileo P, Casanova M, Bertulli R, Meazza C, Gandola L, Navarria P, Collini P, Gronchi A, Olmi P, et al: Rhabdomyosarcoma in adults. A retrospective analysis of 171 patients treated at a single institution. Cancer 98: 571-580, 2003.

4. Agaram NP, Chen CL, Zhang L, LaQuaglia MP, Wexler L and Antonescu CR: Recurrent MYOD1 mutations in pediatric and adult sclerosing and spindle cell rhabdomyosarcomas: Evidence for a common pathogenesis. Genes Chromosomes Cancer 53: 779-787, 2014.

5. Nascimento AF and Fletcher CD: Spindle cell rhabdomyosarcoma in adults. Am J Surg Pathol 29: 1106-1113, 2005.

6. Hawkins DS, Gupta AA and Rudzinski ER: What is new in the biology and treatment of pediatric rhabdomyosarcoma? Curr Opin Pediatr 26: 50-56, 2014.

7. Eichenmüller M, Hemmerlein B, von Schweinitz D and Kappler R: Betulinic acid induces apoptosis and inhibits hedgehog signalling in rhabdomyosarcoma. Br J Cancer 103: 43-51, 2010

8. Petrova R and Joyner AL: Roles for Hedgehog signaling in adult organ homeostasis and repair. Development 141: 3445-3457, 2014.

9. Amakye D, Jagani Z and Dorsch M: Unraveling the therapeutic potential of the Hedgehog pathway in cancer. Nat Med 19: 1410-1422, 2013. 
10. Kelleher FC, Cain JE, Healy JM, Watkins DN and Thomas DM: Prevailing importance of the hedgehog signaling pathway and the potential for treatment advancement in sarcoma. Pharmacol Ther 136: 153-168, 2012.

11. Nakamura S, Nagano S, Nagao H, Ishidou Y, Yokouchi M, Abematsu M, Yamamoto T, Komiya S and Setoguchi T: Arsenic trioxide prevents osteosarcoma growth by inhibition of GLI transcription via DNA damage accumulation. PLoS One 8: e69466, 2013.

12. Aberger F and Ruiz I Altaba A: Context-dependent signal integration by the GLI code: The oncogenic load, pathways, modifiers and implications for cancer therapy. Semin Cell Dev Biol 33: 93-104, 2014.

13. Kasper M, Regl G, Frischauf AM and Aberger F: GLI transcription factors: Mediators of oncogenic Hedgehog signalling. Eur J Cancer 42: 437-445, 2006.

14. Roberts WM, Douglass EC, Peiper SC, Houghton PJ and Look AT: Amplification of the gli gene in childhood sarcomas. Cancer Res 49: 5407-5413, 1989.

15. Lynn M, Shah N, Conroy J, Ennis S, Morris T, Betts D and O'Sullivan M: A study of alveolar rhabdomyosarcoma copy number alterations by single nucleotide polymorphism analysis Appl Immunohistochem Mol Morphol 22: 213-221, 2014.

16. Matsumoto T, Tabata K and Suzuki T: The GANT61, a GLI inhibitor, induces caspase-independent apoptosis of SK-N-LO cells. Biol Pharm Bull 37: 633-641, 2014.

17. Lin TL and Matsui W: Hedgehog pathway as a drug target: Smoothened inhibitors in development. Onco Targets Ther 5: 47-58, 2012.

18. Ruat M, Hoch L, Faure H and Rognan D: Targeting of Smoothened for therapeutic gain. Trends Pharmacol Sci 35: 237-246, 2014.

19. Pan S, Wu X, Jiang J, Gao W, Wan Y, Cheng D, Han D, Liu J, Englund NP, Wang Y, et al: Discovery of NVP-LDE225, a Potent and Selective Smoothened Antagonist. ACS Med Chem Lett 1: 130-134, 2010

20. Kim J, Tang JY, Gong R, Kim J, Lee JJ, Clemons KV, Chong CR, Chang KS, Fereshteh M, Gardner D, et al: Itraconazole, a commonly used antifungal that inhibits Hedgehog pathway activity and cancer growth. Cancer Cell 17: 388-399, 2010.

21. Watts JM and Tallman MS: Acute promyelocytic leukemia: What is the new standard of care? Blood Rev 28: 205-212, 2014.

22. Kim J, Lee JJ, Kim J, Gardner D and Beachy PA: Arsenic antagonizes the Hedgehog pathway by preventing ciliary accumulation and reducing stability of the Gli2 transcriptional effector. Proc Natl Acad Sci USA 107: 13432-13437, 2010.

23. Lauth M, Bergström A, Shimokawa T and Toftgård R: Inhibition of GLI-mediated transcription and tumor cell growth by smallmolecule antagonists. Proc Natl Acad Sci USA 104: 8455-8460, 2007.

24. Laurendeau I, Ferrer M, Garrido D, D'Haene N, Ciavarelli P, Basso A, Vidaud M, Bieche I, Salmon I and Szijan I: Gene expression profiling of the hedgehog signaling pathway in human meningiomas. Mol Med 16: 262-270, 2010.

25. Forus A, Florenes VA, Maelandsmo GM, Meltzer PS, Fodstad O and Myklebost O: Mapping of amplification units in the q13-14 region of chromosome 12 in human sarcomas: some amplica do not include MDM2. Cell Growth Differ 4: 1065-1070, 1993.

26. Prigent $C$ and Dimitrov S: Phosphorylation of serine 10 in histone H3, what for? J Cell Sci 116: 3677-3685, 2003.

27. Gu Y, Rosenblatt J and Morgan DO: Cell cycle regulation of CDK2 activity by phosphorylation of Thr160 and Tyr15. EMBO J 11: 3995-4005, 1992.

28. Loughery J, Cox M, Smith LM and Meek DW: Critical role for p53-serine 15 phosphorylation in stimulating transactivation at p53-responsive promoters. Nucleic Acids Res 42: 7666-7680, 2014.
29. Soussi T and Béroud C: Significance of TP53 mutations in human cancer: A critical analysis of mutations at $\mathrm{CpG}$ dinucleotides. Hum Mutat 21: 192-200, 2003.

30. Burlacu A: Regulation of apoptosis by Bcl-2 family proteins. J Cell Mol Med 7: 249-257, 2003.

31. Hyman JM, Firestone AJ, Heine VM, Zhao Y, Ocasio CA, Han K, Sun M, Rack PG, Sinha S, Wu JJ, et al: Small-molecule inhibitors reveal multiple strategies for Hedgehog pathway blockade. Proc Natl Acad Sci USA 106: 14132-14137, 2009.

32. Ragazzini P, Gamberi G, Pazzaglia L, Serra M, Magagnoli G, Ponticelli F, Ferrari C, Ghinelli C, Alberghini M, Bertoni F, et al: Amplification of CDK4, MDM2, SAS and GLI genes in leiomyosarcoma, alveolar and embryonal rhabdomyosarcoma. Histol Histopathol 19: 401-411, 2004.

33. Graab U, Hahn H and Fulda S: Identification of a novel synthetic lethality of combined inhibition of hedgehog and PI3K signaling in rhabdomyosarcoma. Oncotarget 6: 8722-8735, 2015.

34. Raju GP: Arsenic: A potentially useful poison for Hedgehogdriven cancers. J Clin Invest 121: 14-16, 2011.

35. Kim J, Aftab BT, Tang JY, Kim D, Lee AH, Rezaee M, Kim J, Chen B, King EM, Borodovsky A, et al: Itraconazole and arsenic trioxide inhibit Hedgehog pathway activation and tumor growth associated with acquired resistance to smoothened antagonists. Cancer Cell 23: 23-34, 2013.

36. Au WY, Tam S, Fong BM and Kwong YL: Determinants of cerebrospinal fluid arsenic concentration in patients with acute promyelocytic leukemia on oral arsenic trioxide therapy. Blood 112: 3587-3590, 2008

37. Liu Q, Hilsenbeck S and Gazitt Y: Arsenic trioxide-induced apoptosis in myeloma cells: p53-dependent G1 or G2/M cell cycle arrest, activation of caspase- 8 or caspase- 9 , and synergy with APO2/TRAIL. Blood 101: 4078-4087, 2003.

38. Lunghi P, Tabilio A, Lo-Coco F, Pelicci PG and Bonati A Arsenic trioxide (ATO) and MEK1 inhibition synergize to induce apoptosis in acute promyelocytic leukemia cells. Leukemia 19: 234-244, 2005.

39. Downward J: How BAD phosphorylation is good for survival. Nat Cell Biol 1: E33-E35, 1999.

40. Zha J, Harada H, Yang E, Jockel J and Korsmeyer SJ: Serine phosphorylation of death agonist BAD in response to survival factor results in binding to 14-3-3 not BCL-X(L). Cell 87: 619-628, 1996.

41. Han YH, Kim SZ, Kim SH and Park WH: Arsenic trioxide inhibits the growth of Calu- 6 cells via inducing a $\mathrm{G} 2$ arrest of the cell cycle and apoptosis accompanied with the depletion of GSH. Cancer Lett 270: 40-55, 2008.

42. Jiang L, Wang L, Chen L, Cai GH, Ren QY, Chen JZ, Shi HJ and Xie $\mathrm{YH}: \mathrm{As}_{2} \mathrm{O}_{3}$ induces apoptosis in human hepatocellular carcinoma HepG2 cells through a ROS-mediated mitochondrial pathway and activation of caspases. Int J Clin Exp Med 8: 2190-2196, 2015.

43. Lu TH, Su CC, Chen YW, Yang CY, Wu CC, Hung DZ, Chen CH, Cheng PW, Liu SH and Huang CF: Arsenic induces pancreatic $\beta$-cell apoptosis via the oxidative stress-regulated mitochondriadependent and endoplasmic reticulum stress-triggered signaling pathways. Toxicol Lett 201: 15-26, 2011.

44. Wu X, Shi J, Wu Y, Tao Y, Hou J, Meng X, Hu X, Han Y, Jiang W, Tang S, et al: Arsenic trioxide-mediated growth inhibition of myeloma cells is associated with an extrinsic or intrinsic signaling pathway through activation of TRAIL or TRAIL receptor 2. Cancer Biol Ther 10: 1201-1214, 2010. 